\title{
Morphological Changes in the Hepatic Tissue at the Impact of Industrial Copper-bearing Dust in the Experiment
}

\author{
Khamida R. Abdikadirova, Kymbat Ye. Amreyeva*, Saule B. Zhautikova, Olga A. Kostyleva, Fatima S. Abikenova, \\ Bibigul T. Chergizova, Yulia P. Talaspekova, Saule Sh. Atshabarova \\ Department of Pathology, Non-Profit Joint-Stock Company “Karaganda Medical University”, Nutrition and Hygiene, Morphology \\ and Physiology, Gogol 40, Karaganda 1000008, Kazakhstan
}

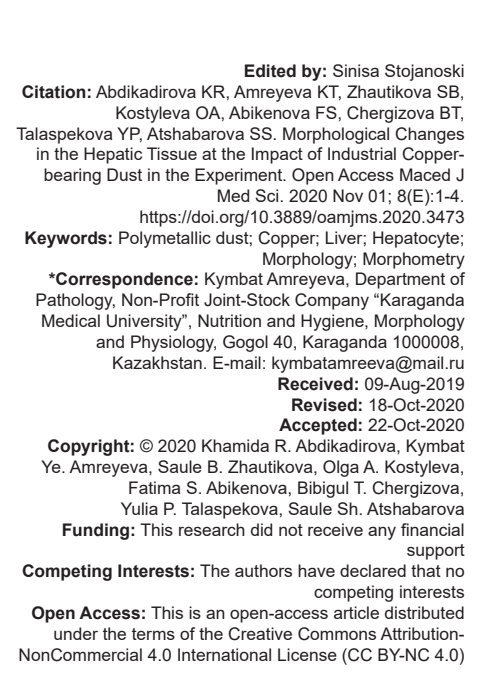

\section{Introduction}

Despite the high level of technology in many workplaces of non-ferrous and ferrous metallurgy, as well as the mining industry, the health of workers is still affected by a complex of harmful production factors, leading of which is polymetallic dust with complex chemical composition and their aerosols containing all the main components of the ore that has fibrogenic, general toxic, and combined effects [1], [2], [3], [4], [5].

A feature of the dust of polymetallic mines is the content of highly toxic metals ( $\mathrm{Zn}, \mathrm{Cu}, \mathrm{Pb}, \mathrm{Co}$, etc.), which have expressed hepatotropic effect [6], [7], [8], [9], [10].

Prolonged inhalation of industrial dust leads to the formation of a "dust depot" in the lungs containing the main components of polymetallic ore. Contact of polymetallic dust with the mucous membranes of the upper respiratory tract, and then its retention in the lung tissue may cause dusty bronchitis and pneumoconiosis. The resorptive general toxic effect of metals is the cause of metabolic disturbances, the development of functional changes in the nervous system, liver, and other organs [11], [12], [13], [14], [15], [16].

It is known that the expressed pathological changes develop both in the passage of intake and elimination of toxic compounds. The main chemicals in the composition of polymetallic dust that has entered through the respiratory organs and the gastrointestinal tract are excreted in addition to the bronchopulmonary organs, the kidneys and the intestines, with the participation of the liver [3], [4], [8], [17].

An analysis of domestic and foreign literature on this issue has shown that the materials devoted to a comprehensive study of the direct effect of copper (Cu)-containing polymetallic dust on the structure and function of the liver are few and fragmentary.

In this regard, experimental studies are relevant to the study of morphofunctional pathological processes developing in the liver at the impact of $\mathrm{Cu}$ dust in various periods of observation.

The aim of the work is to study the morphological changes in the hepatic tissue at the impact of polymetallic Cu dust. 


\section{Materials and Methods}

An experimental study was conducted on outbred white male rats with an initial weight of 120 $170 \mathrm{~g}$. Experimental animals were divided into four groups and the morphofunctional state of the liver tissue was studied in rats exposed to $\mathrm{Cu}$-containing (Cu-0.6\%) polymetallic dust for 30,90 , and 180 days with the control group.

The animals were fed on the usual diet of the vivarium. Polymetallic dust of the Balkhash Mining and Metallurgical Complex with a Cu content (Cu-0.6\%) with a size of 2-5 mg was injected once intratracheally as a suspension of $50 \mathrm{mg}$ of dust in $1.0 \mathrm{ml}$ of saline according to the standard technique. Control animals were injected with $1 \mathrm{ml}$ of saline. For dynamic observation, animals were slaughtered in 1, 3, and 6 months with the control group using instant decapitation.

For histological and morphometric studies, the liver tissue was fixed in a $10 \%$ solution of neutral formalin; then, according to the standard technique, they were filled in paraffin. Microtome sections were prepared from paraffin blocks with a thickness of 5-7 micron, then stained (with hematoxylin-eosin and picrofuchsin according to Van Gieson method) using survey techniques. A histochemical reaction with a benzidine test was also performed on paraffin sections to detect the deposited $\mathrm{Cu}$ in liver tissue hepatocytes [18].

Morphometric studies were performed using the point-counting method with a measuring graticule for cytohistostereometric studies with 100 test-points in four small squares [19].

\section{Results}

After 30 days at the initial time of the experiment, microscopic examination of the liver tissue showed microcirculation disorders in the form of a plethora of central veins and adjacent acini. The central veins are dilated with swollen vacuolated endothelium and often subjected to desquamation. Focal necrosis of the parenchyma, varying severity of hepatocyte protein dystrophy, intracellular cholestasis, and welldefined lymphomacrophagous cell clusters occurred in the lobule. Portal tracts showed plasma soaking and fibrinoid changes in the walls of blood vessels and bile ducts with pronounced perivascular productive reaction. The stroma of the portal tracts was swollen with loose lymphoid cell infiltration (Figure 1a). Hypertrophy of Kupffer's cells was noted and the latter erupted into the lumen of dilated sinusoids.

Histological sections with a benzidine sample showed that the reaction product for $\mathrm{Cu}$ was distributed in the cytoplasm of Kupffer cells and hepatocytes in the form of many small grains, which sometimes filled the entire cytoplasm of cells (Figure 1b).

Morphometric examination of liver tissue at 30 days showed $V v$ necrosis increasing in 320 times in Group 2 ( $p<0.001)$, Vv infiltrates - in 121 times $(p<0.001), V v$ dystrophic altered hepatocytes - in 19.91 times $(p<0.001), V v$ dual-core cells - in 23 times $(p<0.01)$, and $V v$ fibrosis - in 2.82 times $(p<0.001)$ in comparison with Group 1. Vv portal tracts are not reliably changed (Table 1 ).

After 90 days, microcirculation disorders persisted in the liver tissue. It was noted the increasing of dystrophic and necrotic changes of hepatocytes, as well as sclerotic changes of the portal tracts, where there was lymphoid cell infiltration, proliferation of the bile ducts, and hyalinosis of blood vessels, often to complete obliteration of the lumen.

The walls of the central veins were thickened due to the proliferation of thin bundles of collagen fibers in the wall. A productive reaction was expressed perivascular (Figure 2).

In the lumen of the central veins clusters of dust particles were found, which penetrated and were detected, parietally in the lumen of the adjacent capillary sinusoids. Dust particles of various sizes were found in the cytoplasm of hepatocytes. The benzidine test for the presence of "deposited" Cu remained positive. Stellate reticuloendotheliocytes also contained $\mathrm{Cu}$ pigment in their cytoplasm.

In 90 days in Group 3, there were also the following morphometric parameters increasing in comparison with the control group: $\mathrm{V} v$ necrosis - in 522 times $(p<0.001), V v$ infiltrates - in 395 times $(p<0.001), V v$ dystrophic altered hepatocytes - in 26.7 times $(p<0.001), V v$ dual-core cells - in 314 times $(p<0.01)$, and $V_{v}$ fibrosis - in 13.27 times $(p<0.001)$ (Table 1).

By the end of the 180 days of the experiment, trophico-circulatory disorders persisted in the liver, accompanied by an increase in dystrophic changes, both in the lobule and in the portal tracts (Figure. 3a). The walls of the central veins and vessels of the portal tracts were thickened, the latter were hyalinized, and

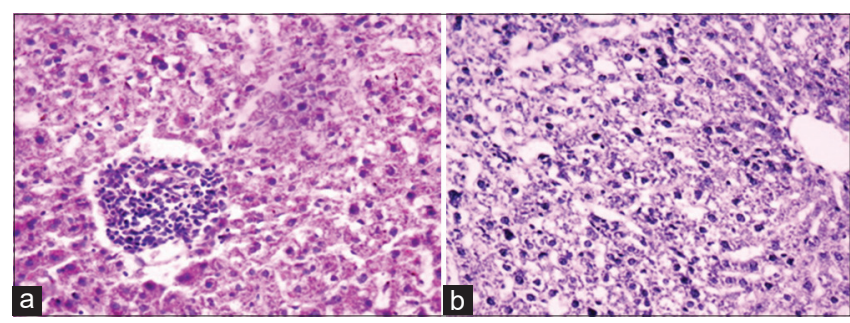

Figure 1: Thirty days of the experiment (a) portal hepatitis. Moderate stromal swelling of portal tracts, lymphocytic infiltration; Staining with hematoxylin and eosin. Magnification: 16× approx. 7 (b) Intracellularly deposited copper. Many small granules in the cytoplasm of hepatocytes (dust is indicated by arrows). Benzidine test. Magnification: $16 \times$ approx. 7 
Table 1: Morphometric parameters of the liver tissue of animals at the impact of Cu-containing polymetallic dust on the $30^{\text {th }}, 90^{\text {th }}$, and $180^{\text {th }}$ day of the experiment $(\mathrm{M} \pm \mathrm{m})$

\begin{tabular}{|c|c|c|c|c|}
\hline Index & Group 1 & Group 2 & Group 3 & Group 4 \\
\hline & $n=6$ & $n=6$ & $n=6$ & $n=6$ \\
\hline Vv necrosis & $0.010 \pm 0.0001$ & $3.200 \pm 0.610^{\star \star \star}$ & $5.220 \pm 0.470^{\star \star \star}$ & $1.220 \pm 0.640$ \\
\hline Vv infiltrates & $0.010 \pm 0.008$ & $1.210 \pm 0.150^{\star \star \star}$ & $3.950 \pm 0.260^{\star \star \star}$ & $4.210 \pm 0.700^{\star \star \star}$ \\
\hline Vv portal tracts & $4.800 \pm 0.230$ & $5.300 \pm 0.270$ & $5.470 \pm 0.460$ & $7.550 \pm 0.860^{\star}$ \\
\hline Vv dystrophic altered hepatocytes & $1.090 \pm 0.010$ & $21.700 \pm 0.630^{* * *}$ & $29.100 \pm 2.870^{\star * *}$ & $37.160 \pm 2.470^{\star * *}$ \\
\hline Vv dual-core cells & $0.010 \pm 0.001$ & $0.230 \pm 0.050^{\star *}$ & $3.140 \pm 0.630^{\star *}$ & $4.1105 \pm 0.710^{\star \star \star}$ \\
\hline Vv fibrosis & $0.110 \pm 0.005$ & $0.310 \pm 0.005^{* * *}$ & $1.460 \pm 0.150^{* * *}$ & $5.950 \pm 1.001^{\star \star *}$ \\
\hline
\end{tabular}

moderate stroma fibrosis was observed (Figure. 3b). Parietal aggregation of red blood cells was often marked. The color of the hepatocyte lobules acquired a mosaic character. The volume fraction of hepatocytes binuclear hepatocytes significantly increased.

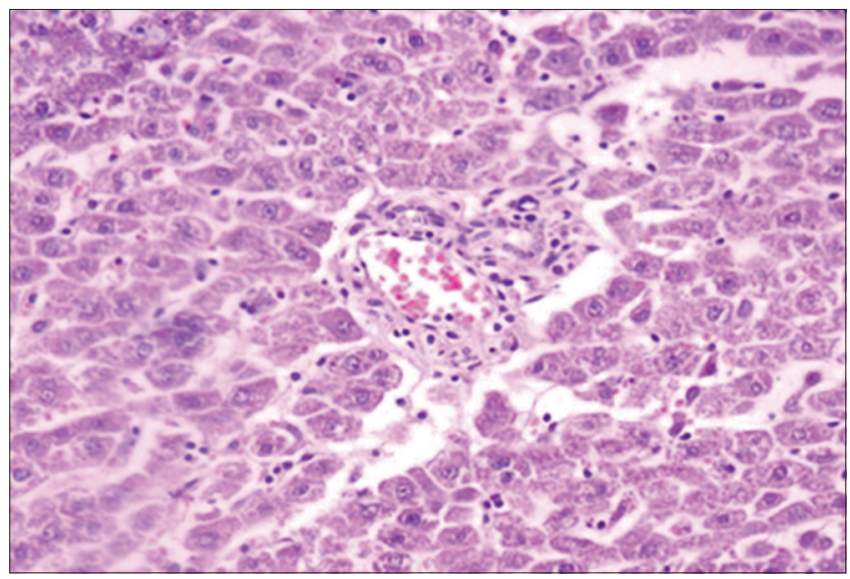

Figure 2: Ninety days of the experiment; portal hepatitis. Lymphoid cell infiltration of portal tracts, proliferation of the bile ducts, hyalinosis of the vessel walls. Staining with hematoxylin and eosin. Magnification: 16× approx. 7

The benzidine test for the presence of "deposited" Cu remains positive and dust particles of various sizes are found throughout the entire cytoplasm of the hepatocytes.

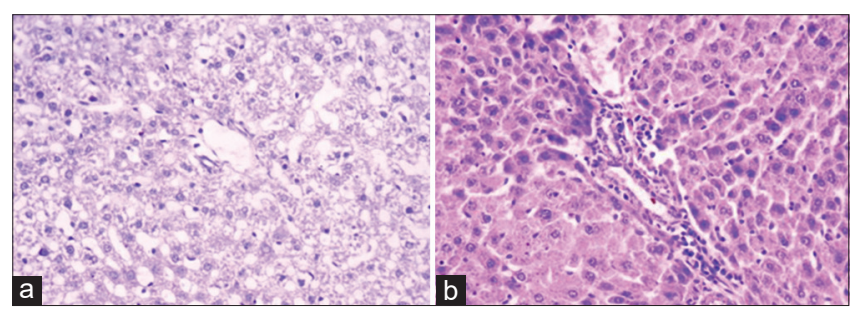

Figure 3: One hundred eighty days of the experiment; (a) hydropic degeneration of the hepatocytes of the centrolobular zone. Staining with hematoxylin and eosin. Magnification: 16× approx. 7. (b) Lymphomacrophagal infiltration of the portal tracts, moderate fibrosis of the stroma. Staining by hematoxylin and eosin. Magnification: $16 \times$ approx. 7

In Group 4, compared to the control group, there is an increase of $\mathrm{Vv}$ infiltrates - in 421 times $(p<0.001), V v$ dystrophic altered hepatocytes - in 34.09 times $(p<0.001), V v$ dual-core cells - in 411 times $(p<0.001)$, and $V v$ fibrosis - in 54.09 times $(p<0.001)$ (Table 1).

\section{Discussion}

Functional disorders were observed in the liver tissue of experimental animals at the impact of dust with a Cu content of $0.6 \%$ for 30 days: In the cytoplasm, the content of free lipids increases in liver cells and stellate reticuloendothelial cells, indicating an increase in destructive changes in the cytoplasmic membranes and membrane complexes. These changes were accompanied by accumulation of $\mathrm{Cu}$ in the liver cells at this period of the experiment and were confirmed by morphometric and morphostatistical data. The accumulation of $\mathrm{Cu}$, both intracellularly and in the stroma of the organ, increased trophico-circulatory disorders, which, in turn, aggravated alterative-dystrophic and inflammatory changes in the organ.

During this period of dusting, the cytotoxic effect of dust was traced, which was manifested by dystrophic and necrotic changes of hepatocytes and macrophages, as well as by impaired microcirculation, a perivascular productive reaction, and infiltration of vessel walls. The results of morphometric studies showed that there is a significant increase in $\mathrm{Vv}$ necrosis in 320 times, $\mathrm{Vv}$ infiltrates - in 121 times, and $V v$ dystrophic altered hepatocytes - in 19.91 times in comparison with the control group. In addition, the permeability of the vessel walls was also impaired, which does not exclude the morphological component of the immune inflammation of the vessel walls.

For 90 days in the liver of experimental animals, signs of non-specific reactive hepatitis were kept, and the character of portal and persistent was acquired. It was noted that the growth of dystrophic and necrotic changes of hepatocytes, as well as sclerotic changes of the portal tracts, where there was lymphoid cell infiltration, proliferation of the bile ducts, often up to complete obliteration of the lumen. In morphometric studies, there was also a significant increase in the following morphometric parameters in comparison with the control group: Vv necrosis - in 522 times, Vv infiltrates - in 395 times, and $\mathrm{Vv}$ dystrophic altered hepatocytes - in 26.7 times. The walls of the central veins were thickened due to the proliferation of thin bundles of collagen fibers in the wall. Perivascular was expressed a productive reaction. In liver tissue, a marked decrease in reparative processes was observed. 
On the 180 days of the experiment, trophicocirculatory changes were kept in the liver, with a marked increase in degenerative phenomena, both in the lobule and in the portal tracts, and pronounced stromal fibrosis has been detected.

Thus, the initial mechanism in the development of liver damage is toxic damage to stellate reticuloendothelial cells followed by alteration of hepatocytes. From the data obtained, it becomes obvious that the toxic effect of $\mathrm{Cu}$ or its compounds on the microvasculature takes place, with the subsequent development of trophico-circulatory disorders.

\section{Conclusions}

The complex histomorphological microscopic study showed that prolonged exposure to polymetallic dust with $0.6 \% \mathrm{Cu}$ concentration leads to marked changes in the reactive liver, followed by transformation into portal-type hepatitis, there is a tendency for pure $\mathrm{Cu}$ to accumulate in the hepatocyte cytoplasm that can be explained by the breakdown of the phagocytic function of liver macrophages, and the ways of eliminating dust from the body.

\section{References}

1. Guselnikov SR, Gogoleva OI, Lipatov GY, Adrianovsky VI, Samylkin AA. Professional morbidity of workers engaged in obtaining refined copper. Med Tr Prom Ekol. 2015;9:46-47.

2. Lozova EV, Karimova LK, Gainullina MK, Mavrina LN, Bagul NA, Salimgareeva TM. Hygienic assessment of working conditions of workers of mining and processing plants. Med Tr Prom Ekol. 2015;3:121-7.

3. Sadykov MN, Otarov EZ, Asenova LX, Makanova UK, et al. Assessment of working conditions of mining workers. Med Tr Prom Ekol. 2017;3:71-3.

4. Serebryakov PV, Kartashev OI, Fedina IN. Clinical and hygienic evaluation of health state of copper production workers in Far North. Med Tr Prom Ekol. 2016;1:25-8.

PMid:27048139

5. Lipatov GY, Adrianovsky VI, Konstantinov VG, Gilyova YM.
Mortality from malignant neoplasms of workers engaged in the enrichment of copper-containing ores. Ural Honey Zhur. 2010;1(66):5-7.

6. Izmerov NF, Kovalevsky EV, Rukavishnikov VS. Industria dust. Aerosols predominantly fibrogenic action. In: Izmerov NF, Chuchalin AG, editors. Occupational Respiratory Diseases. Moscow, Russia: M: GEOTAR-Media; 2015. p. 44-58.

7. Kavasaki HA. Mechanistic review of silica-indused inhalation toxicity. Inhal Toxicol. 2015;27(8):363-77.

PMid:26194035

8. Pankova VB. The Current problems of diagnostics and expertise of occupational diseases of the upper respiratory tract. Vestn Otorhinolaryngol. 2015;80(5):14-8. https://doi.org/10.17116/ otorino201580514-18 PMid:26525465

9. Shorin SS. Environmental factors of industrial cities that worsen the health of the population, and ways to solve them. Vectnik Karagandinskogo univerciteta. Seria biologia. Medicina. Giografia. 2014;2:35-43.

10. Farshatova ER, Menshikova IA, Kamilov FK. The influence of the metals contained in copper-zinc sulfide ores, on bone metabolism. Med Vectnic Bashkortostan. 2014;4:57-9.

11. Pavlov VN, Bekmukhambetov EZ, Teregulova ZS, Mamyrbaev AA, Teregulov BF, Ishemgulov RR. The evaluation reproductive health of men living and working in conditions of mining technogenesis. Med Bull Bashkortostan. 2015;10(3):103-6.

12. Tataeva RK, Mussina AA, Burumbaeva MB. Morphological characteristics of liver tissue inhalation polymetallic aerosol condensation. News Natl Acad Sci Repub Kazakhstan Ser Biol Med. 2014;4(302):43-6.

13. Ibrayeva LK, Battakova JE, Amanbekova AU, Chanturia GR The character of energy changes in the activity of enzymes in the blood of rats under the action of finely dispersed aerosols of polymetallic dust and alimentary correction. Fundam Issled 2011;9(2):251-3.

14. Shaimardanova GM. Peroxidation in the lungs, liver and kidneys of rats with chronic exposure of polymetallic dust. Uspechy Sovremennogo Ectectvozhnania. 2008;8:19-22.

15. Kuz'mina LP, Izmerova NI, Burmistrova TB, Druzhinin VN Patomorfoz sovremennyh form professional'nyh zabolevanij. Med Tu Prom Jekol. 2008;6:18-24.

16. Kupsha El. Morphofunctional characteristic of the nuclei of hepatocytes of mice with lead intoxication. Mezhdunarodnyy Nauchno Issled Zhur. 2017;11:27-2.

17. Nasution RS, Yerizel E, Chaidir Z, Zein R. Protective effects of nothopanax scutellarium on hepatotoxicity of copper (II) induced to experimental. Open Access Maced J Med Sci 2020;8:283-6. https://doi.org/10.3889/oamjms.2020.4238

18. Pirs E. Histochemistry. Netherlands: Elsevier; 1962. p. 962.

19. Avtandilov GG. Morphometry in Pathology. Moscow: Meditsina; 1973. p. 152-171. 